\title{
A institucionalização da educação em questão
}

\author{
The institutionalization of the education under discussion
}

Hans-Georg Flickinger*

\section{Resumo}

O texto reflete acerca das atuais tendências políticas e organizacionais em andamento e suas implicações sobre a mudança de rumos da educação no Brasil e na Alemanha. O autor preocupa-se em avaliar o quanto essas mudanças contribuem para a descaracterização da educação como processo de formação (Bildung) e, especialmente, as suas consequências para o dia a dia profissional. Inicia com a identificação das políticas recentemente impostas ao campo educacional, esclarece a base constitucional nos dois países e, na sequência, assinala algumas armadilhas dessas políticas. Por fim, aponta para a verdadeira amplitude dos problemas causados por tais políticas, com destaque para a ideologização, a subsidiariedade e a filantropia.

Palavras-chave: Bildung. Filantropia. Ideologização. Políticas educacionais. Subsidiariedade.

\section{Abstract}

The text reflects on current political and organizational trends and their implications for changing directions in education in Brazil and Germany. The author is concerned with assessing how much these changes contribute to the decharacterization of education as a process of formation (Bildung) and, especially, its consequences for the professional daily routines. It begins with the identification of policies recently imposed on the educational field, clarifies the constitutional base in the two countries and, next, points out some pitfalls of these policies. Finally, it points to the real breadth of the problems caused by such policies, especially ideologization, subsidiarity and philanthropy.

Keywords: Bildung. Educational policies. Ideologization. Philanthropy. Subsidiarity.

Recebido em: 25/01/2017 - Aprovado em: 31/05/2017

http://dx.doi.org/10.5335/rep.v24i3.7763

Doutor em Filosofia pela Universidade de Heidelberg, Alemanha. Professor aposentado da Universidade de Kassel, Alemanha. 


\section{Introdução}

Nas últimas décadas, o debate sobre os problemas da educação abordou, antes de tudo, dois focos principais. Por um lado, procura-se salvaguardar a ideia de formação (Bildung) como diretriz-guia do processo educativo; por outro, discutem-se novos princípios de organização cujas consequências para o dia a dia profissional ainda estão pouco claras.

Como já existe um amplo debate sobre os riscos de perdermos de vista a ideia de formação (Bildung), quero preocupar-me com o outro foco, isto é, com as atuais tendências políticas e organizacionais, enquanto condições que mudam os rumos do sistema educacional. Elas podem contribuir para a descaracterização da educação como processo de formação (Bildung). Para entendermos melhor as mudanças, no primeiro item, faz-se necessário resumir, as tendências políticas recentemente impostas ao campo da educação, observadas tanto no Brasil quanto na Alemanha. No segundo, aponto algumas consequências organizacionais desencadeadas pelo rumo novo das políticas educativas. Impostas ao sistema da educação por razões a ele externas, elas criam armadilhas ao processo de educação como um todo. Para saber se as novas estratégias políticas têm sustento legal, no terceiro item, apresento uma ideia geral de sua base constitucional nos dois países referidos. Finalmente, lanço tópicos para investigações mais detidas, capazes de abarcar a verdadeira amplitude dos problemas causados pelas políticas liberais em fase de aperfeiçoamento.

\section{Tendências atuais na política educativa}

Desde o fim do século XX, os esforços contínuos de reformar o sistema educacional, em todos os níveis, vêm ganhando fortes impulsos a partir da internacionalização do mercado de trabalho e da crescente interdependência entre as diversas concepções nacionais da política educativa. Não é possível, é claro, enumerar todas as estratégias responsáveis por essa dinâmica. Basta lembrar as mais profundas, que vêm sendo impostas, ainda que com intensidade diferente, tanto no Brasil quanto na Alemanha.

Juntamente com a internacionalização do campo da educação e a demanda pela mobilidade da força de trabalho, coloca-se o problema de como comparar os diversos modelos nacionais de profissionalização e garantir sua aceitação mútua. Salta aos olhos que, na primeira etapa, ocorreu a padronização internacional dos princípios curriculares. ${ }^{1}$ Com esse passo, buscava-se garantir a compatibilidade 
das qualificações profissionais, assim como facilitar, também, o reconhecimento mútuo dos rendimentos, seu controle e a mobilidade dos alunos.

No entanto, não é nada fácil comparar processos de qualificação baseados em critérios de qualidade diferentes e realizados sob desiguais condições técnico-científicas. Com isso, a solução encontrada foi a quantificação das normas qualitativas e a representação numérica das diretrizes de qualidade que sustentam os currículos. Mesmo que tal transformação da qualidade em critérios quantitativos não consiga retratar completamente a norma qualitativa, ela é tida como o único caminho para comparar os modelos nacionais de educação e profissionalização.

Essa interpretação quantitativa dos processos educativos tornou-se a condição imprescindível para outra estratégia inusitada da política educativa, a saber, sua economização. Como já caraterizada por Hegel, em Filosofia do direito (2010), a economia é uma ciência que visa descobrir "os princípios simples da coisa, o entendimento nela agindo e regendo" (2010, nota do § 189). O filósofo destaca, desse modo, o fato de que, ao tratar das relações entre coisas, a economia pouco se preocupa com os efeitos que isso terá sobre os seres humanos. O homem visto como capital humano torna-se a expressão caraterística dessa atitude. A economização do processo educativo prioriza, portanto, as necessidades econômicas em detrimento das demandas sociais e, logo, também das pedagógicas. Trata-se da submissão do processo educativo ao domínio dos números e da estatística. Faz-se da relação entre input/output o critério último de sua avaliação. Quanto maior o output - contado, por exemplo, pelo número de formandos ou de eventos, publicações, etc. -, tanto maior a chance de as instituições obterem recursos como input ao seu trabalho.

Ultimamente, observa-se uma consequência como que natural das três estratégias referidas, pois, da padronização, quantificação e economização do campo educacional para a entrega dessa área à lógica do mercado é um passo apenas; um passo que, entretanto, dá conta do espírito liberal das atuais reformas. Seus primeiros sinais afetam todas as instituições educativas, sejam elas os jardins de infância, as escolas, as universidades e até mesmo os projetos no campo da pedagogia não formal. ${ }^{2}$ Fala-se da transformação do campo da educação num mercado de oferta e procura, no qual as instituições obrigam-se a elaborar um perfil próprio, para alcançar destaque na concorrência com as demais. $\mathrm{E}$ isso vale tanto para as instituições privadas quanto, cada vez mais, para as públicas. Em consequência, a política vê-se solicitada a atribuir maior autonomia às instituições educativas. $\mathrm{O}$ assim criado pluralismo liberal faz da educação um campo de produção de mercadorias que concorrem, no mercado, mediante o menor preço, com a boa apresentação, a dependência das demandas da clientela, a sutil propaganda, etc. 
As estratégias expostas revelam um projeto de reforma em si coerente, porém destrutivo, quando se considera a educação como processo de formação (Bildung). Entre os efeitos altamente questionáveis dessa política, está a substituição da ideia de formação pela de competência , como diretriz prioritária. ${ }^{3}$ Uma substituição que vai, obviamente, na contramão da tradição pedagógica iluminista. $\mathrm{O}$ apelo de Humboldt aponta para a armadilha contida na ideia de competência, quando diz: "O que deveria prosperar, no homem, deve ter origem no seu interior, e não lhe deve ser dado de fora" (1988, p. 79). Ora, competências são nada mais do que qualificações a serviço da lógica econômica, em detrimento da vontade, da inclinação e do potencial da pessoa que busca sua formação. Como se isso não bastasse, a competência, uma vez alcançada, dificilmente conseguirá sustentar uma carreira profissional linear; muito pelo contrário, a necessidade de reformular as competências, no aperfeiçoamento contínuo, vale, hoje, para a maioria dos profissionais. Nesse sentido, a competência profissional, como objetivo prioritário da educação, coincide, na verdade, com a lógica liberal forçada pelas estratégias políticas recentes.

Outro aspecto pouco mencionado das políticas descritas, embora caiba no projeto da reforma institucional, é o excesso da burocratização dos processos educativos. Sua presença na prática pedagógica cotidiana incomoda bastante. Não se pode negar, evidentemente, que instituições - e não somente as públicas - precisem de regras burocráticas para seu bom funcionamento. Em nome da igualdade de tratamento da clientela e com vistas à impessoalidade das decisões, a atuação institucional precisa ser calculável e transparente. Tal qualidade é importante sobretudo para processos nos quais a instituição lida com uma clientela diversificada e casual, como no caso da educação. Contudo, a burocracia vê-se numa situação contraditória e constrangedora. Por um lado, todos devem ser tratados como iguais, sem favorecimentos, de modo que a burocracia tende a atuar com base na assim chamada lógica condicional. Isso significa que, em condições idênticas, as decisões deverão ser sempre as mesmas, levando ao efeito colateral da rotinização do trabalho burocrático. Por outro, a burocratização deve respeitar o desafio pedagógico, que consiste em fazer jus às condições e às demandas individuais das pessoas envolvidas, isto é, dos alunos e dos profissionais. A causa desse dilema ou armadilha está exatamente naquelas estratégias de padronização, quantificação e economização que já apontamos. Elas favorecem a rotina burocrática, deslocando as demandas individuais de alunos e profissionais para um segundo plano. É, portanto, a aliança entre a rotina burocrática e as estratégias políticas recentes que ameaça desvirtuar o processo educativo.

Outro efeito deletério, ligado à dinâmica da burocratização, é o aumento de conflitos entre os profissionais da educação e os burocratas. Tendo vivido tipos de 
socialização profissional inteiramente diversos, eles desenvolvem compromissos profissionais também diversos. Apoiados em seu saber científico, os educadores voltam-se às necessidades de sua clientela, enquanto os burocratas profissionais visam, antes de tudo, ao funcionamento da instituição, à efetividade da aplicação dos recursos e das medidas, assim como ao respeito pelas regras legais. ${ }^{4}$ Essa diferença entre compromissos leva, não raro, a avaliações da situação concreta inteiramente incompatíveis. Tomemos o exemplo da conduta inadmissível de um aluno. O que o pedagogo acredita ser adequado, como reação individual, pode significar, ao olhar do burocrata, um precedente perigoso, que deveria ser evitado a qualquer custo. Outro exemplo: a aplicação dos recursos torna-se objeto de conflito, pois o pedagogo pode achar necessário aumentar o acesso a tecnologias novas na sala de aula, ao passo que o burocrata está convencido de ter de aplicá-los segundo medidas dadas pela segurança institucional. Infere-se, então, que quanto maior o peso da burocracia, tanto maior será a perda de relevância das demandas pedagógicas.

A dinâmica desencadeada pelas novas estratégias políticas mexe, portanto, com o processo educativo; e é inevitável que atinja, também, as condições institucionais desse processo.

\section{Mudanças institucionais do processo educativo}

Há, sem dúvida, fortes diferenças entre Brasil e Alemanha no que se refere à história de seus sistemas educativos. Na Alemanha, as raízes do sistema público de educação remetem ao início do século XVIII, ao passo que a educação pública, no Brasil, só foi instaurada pelo Estado Novo, não chegando, portanto, a noventa anos de existência. Mesmo com essa diferença histórica, observa-se, hoje, certa semelhança entre os dois sistemas, devido ao compromisso exibido, nos dois casos, em relação à concepção do liberalismo político e às suas consequências sociais.

Essa semelhança entre os dois sistemas de educação pública deve-se ao fato de ambos terem tido um campo de antemão preparado por estruturas já institucionalizadas, a partir do trabalho de organizações religiosas, ligadas às igrejas. O que preparou o solo para ambos os sistemas de educação pública foi, na verdade, o engajamento dessas organizações no sentido de - indiferentes às demandas novas de um mercado de trabalho submisso à dinâmica da sociedade industrial-capitalista - dar às populações uma formação que concordasse com a missão cristã. Com a intervenção ativa do Estado na educação - mais cedo na Alemanha, mais tarde no Brasil -, a concorrência dos institutos públicos de ensino com a educação privada já existente levou, rapidamente, à necessidade de organizar um convívio suportável entre os dois sistemas. A solução foi encontrada no princípio de subsidiariedade, 
respeitado até hoje como que naturalmente nos dois países. Tratarei disso mais adiante.

Esta breve menção à história esclarece, portanto, a origem da concorrência entre dois tipos institucionais; concorrência que segue presente nos sistemas de educação brasileiro e alemão. Há, porém, uma diferença marcante entre ambos, talvez causada pela indicada disparidade histórica entre os dois países: enquanto as instituições privadas dominam ainda, em todos os níveis, o campo brasileiro da educação, o sistema alemão prioriza, hoje, os institutos públicos. Não é este o lugar para detalhar esse aspecto; interessa-nos saber até que ponto a concorrência entre os dois tipos institucionais e as novas estratégias políticas remetem a um fundo comum, isto é, à concepção do liberalismo político. Para abordá-lo, precisamos, primeiro, ter uma noção geral das instituições privadas e públicas que atuam no sistema educativo.

Quanto às instituições privadas, vale destacar pelo menos três aspectos que as diferenciam das instituições públicas. Em primeiro lugar, salta aos olhos a maior liberdade de negociação, por parte das instituições privadas, tanto com os alunos quanto com os profissionais. A legislação civil garante a liberdade contratual como marco geral, dentro do qual se pode escolher a opção que melhor corresponde aos interesses dos mantenedores. A liberdade de escolha vale também em relação às formas institucionais da entidade educativa, oferecidas pelo Código Civil. Segundo: dentro das diretrizes da política educativa, qualquer mantenedora de uma instituição privada define o compromisso ideológico ao qual o trabalho pedagógico deve subordinar-se. Trata-se de uma obrigação trabalhista, que, por exemplo, permite que o profissional não disposto a assumir tal compromisso possa ser demitido por justa causa. $\mathrm{O}$ terceiro aspecto remete à maior flexibilidade na gestão, que dá à instituição privada a chance maior de pôr em experiência conteúdos e formas em seu trabalho. Esta é uma chance importante, entre outras, que lhe permite construir seu perfil próprio, com vistas a uma maior visibilidade no mercado.

É óbvio que as vantagens das instituições privadas representam, por sua ausência, as desvantagens das instituições públicas. Entretanto, vale também o inverso. Não é apenas a gratuidade do ensino, garantida pelas Constituições, que atrai alunos das diversas camadas sociais a entrar nos sistemas públicos. Importa salientar a qualificação do educador profissional que, aprovado em concurso, tem de cumprir exigências previstas em lei. Sua estabilidade de emprego serve para lhe dar maior segurança, autonomia e chance de ver sua identidade intelectual respeitada. Outro aspecto tem a ver com os recursos da instituição pública, que são definidos pelo orçamento público, sem depender de contribuições dos alunos, e oferecem maior segurança ao planejamento e às diretrizes pedagógicas. Por fim, não há como fazer prevalecer uma ou outra ideologia como referencial do trabalho 
profissional. O trabalho pedagógico, nos institutos públicos, deve ser ideologicamente neutro, aceitando a pluralidade de convicções.

Essas poucas indicações devem bastar-nos para apontar as principais linhas de conflito na relação entre os dois tipos institucionais. Dessas linhas, tematizarei apenas três, que são as mais importantes e também preocupantes tanto no Brasil quanto na Alemanha. São elas: a ideologização do trabalho profissional; a vigência do princípio de subsidiariedade; e a luta pelo caráter filantrópico. A seguir, perguntarei de que maneira as estratégias políticas atuais tentam resolver esses conflitos, parecendo-me que o caminho favorecido é o de uma política de assimilação dos dois tipos institucionais.

Comecemos com a ideologização do trabalho profissional. Em contrapartida a instituições públicas da educação, submissas apenas a regras legais ideologicamente neutras, todo detentor de uma entidade privada quer ver sua convicção ideológica realizada na prática do ensino. Entidades ligadas à Igreja, por exemplo, fazem questão de participar no projeto de divulgar diretrizes ético-morais da respectiva religião. O mesmo vale para a orientação antroposófica de Rudolf Steiner, na Escola Waldorf, que pode insistir em que seus profissionais se identifiquem com seus princípios humanistas. Também as seitas fazem uso desse privilégio. Essa autonomia facilita a transformação do campo da educação em um mercado, cujo pluralismo ideológico, cada vez menos transparente, vem não só dificultando aos pais a escolha de uma escola adequada para os filhos, como também ao Estado o controle do que acontece ideologicamente na instituição. Exemplo típico é a legislação trabalhista, que, na Alemanha, submete os profissionais ao regime específico dos mantenedores. ${ }^{5}$

No que se refere ao princípio de subsidiariedade, importa saber que há uma longa história. Com origem na doutrina social da Igreja Católica, ${ }^{6}$ esse princípio é visto, hoje, como critério geral da política social. Se, por exemplo, em uma determinada área social, houver, por parte de entidades privadas, oferta suficiente de atividades, o poder público não poderá concorrer com seus próprios serviços. $\mathrm{O}$ princípio tem uma função política ambígua. Ele visa, por um lado, motivar e ampliar a participação da sociedade civil nas políticas sociais - um efeito bem visto da perspectiva do liberalismo político -, e, por outro, porém, permitir ao Estado transferir, em larga medida, sua própria responsabilidade social à sociedade civil. São os políticos que encontram, aí, uma situação confortável. No caso de um êxito alcançado em serviço financiado em grande parte pelo orçamento público, eles podem vendê-lo como seu sucesso; em caso de fracasso, porém, é-lhes possível atribuí-lo a outro, isto é, ao trabalho mal feito dos gestores privados. Ora, já que a situação política é confortável para os dois lados, nenhum dos parceiros deseja alterá-la. 
A liberdade ideológica das instituições privadas e o princípio de subsidiariedade formam uma aliança politicamente discutível, pois, graças ao princípio de subsidiariedade, os recursos públicos sustentam concepções educacionais de entidades privadas que, comprometidas com suas ideologias, podem desvirtuar a política educacional do Estado. Trata-se, de fato, de um financiamento público involuntário da ideologização privada da educação.

Sabe-se que a maior parte das organizações privadas que atuam no campo da educação goza do status de organização filantrópica, o que lhes dá vantagens econômicas e estratégicas, entre elas, a redução da carga tributária, desde que os ganhos sejam reinvestidos na realização do trabalho pedagógico. Outra vantagem é a de a organização privada ter autonomia de decisão quanto aos focos principais de suas atividades e à flexibilidade no investimento dos recursos. É uma enorme vantagem, em comparação com as instituições públicas, cujo uso de recursos define-se pelas diretrizes do orçamento político geral. Não raro, acontece, também, a falta de controle do Poder Público sobre as organizações com o status de filantropia, porque ele nem sempre está interessado em perder um ator importante em área de sua própria responsabilidade.

As diferenças consideráveis entre as organizações de ensino públicas e privadas dificultam uma política de educação coerente. Quanto a isso, a situação no Brasil é ainda mais difícil do que na Alemanha, porque se observa, sobretudo naquele país, a reprodução de desigualdades sociais pelos sistemas dados. É que, desde o jardim de infância até a universidade, existe, no Brasil, uma seleção social inegável. Quem puder, pagando mensalidades elevadas, colocar os filhos no jardim da infância e, depois, na escola particular terá grandes chances de vê-los entrar na universidade pública gratuita. Ao passo que os filhos de famílias desprivilegiadas, que tenham de frequentar a escola pública gratuita de qualidade precária, terão, provavelmente, de fazer sacrifícios enormes para conseguir pagar uma universidade particular. De um modo geral, o desnível de qualidade entre esses tipos institucionais reespelha o real desnível social. Um fato ultimamente comprovado também na Alemanha.

Ciente dessa situação embaraçosa, as atuais estratégias da política educativa visam opor ao status quo a assimilação das instituições públicas e privadas. Cada uma é incentivada a incorporar as qualidades positivas da outra. Quanto ao setor público, percebe-se a reestruturação de suas entidades, visando torná-las socialmente mais permeáveis, à base de cotas, que lhes ofereçam maior autonomia de decisão, além de submetê-las à economia do mercado. Recentemente, essas entidades vêm sendo também motivadas a trabalhar em favor de um perfil pedagógico próprio, que as leve a afirmar-se na concorrência com as demais particulares. 
No que tange às instituições privadas, salta aos olhos a intenção política de integrá-las melhor no sistema educativo como um todo, a fim de torná-lo mais coerente. A avaliação uniforme das instituições públicas e privadas mediante rankings, a oferta de incentivos para amenizar os desníveis sociais, por exemplo, via aumento de bolsas, o maior controle dos fins sociais e a cooperação em projetos comuns são claros sinais nesse sentido. Um exemplo típico é a gratificação financeira paga no caso da aceitação de cotas para jovens de origem social marginalizada.

Resumindo: fica bastante claro que as estratégias políticas interferem na organização institucional do sistema de educação. Resta saber se elas são apenas consequência do compromisso com as ideias do liberalismo político e com o esforço contínuo de fortalecer o Estado liberal do Direito.

\section{0 fundo liberal da organização do espaço educativo}

Constatamos uma talvez surpreendente semelhança entre o Brasil e a Alemanha no que diz respeito à institucionalização do sistema educativo em ambos os países. Existe, em ambos os países, uma coexistência de entidades de educação públicas e privadas, de modo que, se as novas estratégias políticas que reforçam essa coexistência e sua implementação institucional encontrarem seu fundamento nas suas respectivas Constituições, poderíamos extrair dela um marco típico do Estado liberal do Direito. Será isso que, a seguir, verificaremos.

$\mathrm{Na}$ Alemanha, a competência de legislar sobre temas da educação cabe aos Estados integrantes da Federação; que decidem até que nível seus diversos modelos educativos são compatíveis entre si. As leis estaduais referentes ao ensino escolar e às universidades são prova disso. Cumpre-se, assim, o artigo 7 do Grundgesetz (como é denominada a Constituição alemã) (DEUTSCHER BUNDESTAG, 1949), segundo o qual cabe ao Poder Púbico garantir o sistema de uma educação abrangente e eficiente. O que importa, aqui, é o fato de o mesmo artigo abrir a porta para a participação de instituições privadas no ensino. Supõe-se, portanto, a cooperação entre o Estado e as entidades privadas. Seu modelo foi confirmado, em 1967, pelo Tribunal Federal Constitucional (Bundesverfassungsgericht), que interpreta o já mencionado princípio de subsidiariedade como norma geral na distribuição das responsabilidades sociais entre o Poder Público e a sociedade civil. Com essa decisão, o tribunal não aceita apenas a atuação prioritária das entidades civis; aceita, simultaneamente, o fato de que esse trabalho possa depender de diretrizes comprometidas com as ideologias propagadas pelos detentores daquelas entidades. Trata-se de um fato de importância maior no campo pré-escolar e no ensino médio, 
nos quais existe uma participação considerável de instituições privadas, ao passo que sua cota no campo acadêmico é, por enquanto, negligenciável. ${ }^{7}$

Há uma variedade de tipos jurídicos que se encontram no sistema de ensino alemão. Essa variedade se deve à possibilidade de a mantenedora da entidade educativa escolher um dos modelos jurídicos do Código Civil, como associação, sociedade de responsabilidade limitada, fundação, entre outros. Essa flexibilidade na adaptação do tipo jurídico às necessidades específicas da mantenedora é, portanto, bem vista. Já o sistema estatal deu, tradicionalmente, preferência ao modelo de instituto público sob a égide direta do Poder Público. Entretanto, as novas estratégias políticas fazem crescer o interesse em transformar as instituições estatais em pessoas jurídicas, a fim de dar-lhes maior autonomia de gerenciamento e de criação de um perfil próprio. Espera-se que consigam, desse modo, corresponder melhor aos novos desafios.

Em contrapartida ao modelo federal alemão, a legislação brasileira, mais especificamente a Constituição de 1988 (BRASIL, 1988), centraliza a educação na responsabilidade da União (art. 205). Aqui, na verdade, o que mais interessa é o fato de - assim como o modelo alemão - ela permitir, nos artigos 206, III, e 209, a colaboração da iniciativa privada. As fundações privadas são, ademais, reconhecidas - nos artigos 19 e 45 da Lei de Diretrizes e Bases da Educação (LDB), de 1996 (BRASIL, 1996) - como elementos constitutivos do sistema educativo. Acontece que, quando o artigo 210 da Constituição fala da competência do legislador de fixar apenas conteúdos mínimos, está-se deixando, com isso, um amplo espaço de ação às entidades privadas, no sentido de diferenciar a base ideológica de seu trabalho profissional. Tem-se aí, portanto, nada mais nada menos do que a consequência do princípio de subsidiariedade. Embora não mencionado, explicitamente, no texto da Magna Carta, esse princípio vê-se reconhecido constitucionalmente, quando se trata da distribuição de competências entre as instituições públicas e privadas. O que significa que se está aceitando e legislando no sentido de um modelo educativo misto.

Quanto à institucionalização do modelo brasileiro, constata-se, novamente, a dita semelhança com a concepção alemã. O legislador brasileiro permite, também, às mantenedoras privadas de entidades educativas escolher entre os tipos organizacionais que o Código Civil oferece. Cada mantenedora pode decidir sobre o tipo institucional que mais lhe provenha. A fundação é, na verdade, hoje, o tipo jurídico preferido; pois, tendo patrimônio próprio e finalidade social, trabalhando sem fins lucrativos e orientada a reinvestir todo lucro na realização de fins sociais, ela se adequa melhor aos objetivos sociais. Não é só isso, porém. A política atual, empunhando a bandeira liberal na sua concepção da educação como mercado, só vem favorecendo o modelo da fundação devido ao fato de que, enquanto pessoa 
jurídica, esta é capaz de movimentar-se melhor no mercado econômico. Afinal, uma fundação assume sozinha a responsabilidade pelas suas finanças e pelo êxito de sua atuação. Mais ainda, com a nova política de equiparar ao máximo possível as instituições públicas com as privadas, cumpre-se outra condição importante com vistas à reestruturação do campo educacional enquanto mercado. É, portanto, a própria Constituição que se vem empenhando em aperfeiçoar a realização de sua ideia político-liberal.

Destacarei, por fim, alguns aspectos nevrálgicos que se evidenciaram ao longo da exposição das redes institucionais alemã e brasileira; aspectos que, no meu entender, mereceriam investigação mais profunda no futuro.

\section{Aspectos nevrálgicos das estratégias políticas}

Como já mencionado, é graças ao seu compromisso com a visão liberal que a institucionalização dos sistemas educativos do Brasil e da Alemanha apresenta forte semelhança organizacional. Entre os aspectos a serem destacados, nessa semelhança, estão: a introdução de estruturas de mercado, a aplicação do princípio de subsidiariedade, a substituição da ideia de formação pela de competência, a autonomia das entidades educativas e a livre escolha dos institutos legais. Tendo em vista o cenário exposto, parece que existem alguns nexos ocultos entre esses aspectos que parecem de crucial importância para o desenvolvimento do sistema educativo.

Em primeiro lugar, pergunta-se se a transformação da educação em mercado de oferta e procura será, de fato, irreversível como estratégia no sentido do aperfeiçoamento do sistema liberal. O favorecimento do cálculo econômico e a padronização do trabalho profissional, de fato, intencionam isso. A mesma suspeita vale em relação à introdução da ideia de competência como objetivo da educação, a qual, frente às exigências do mercado de trabalho moderno, desloca a um plano secundário a ideia de formação (Bildung). Constata-se que a tendência de conceder maior autonomia às instituições educativas também contribui em favor dessa lógica de mercado, já que elas se tornam, assim, parceiras na livre negociação.

Em segundo lugar, pergunta-se se a obrigação de submeter as entidades educativas à lógica do mercado poderia minar a validade do princípio de subsidiariedade. Faz ainda sentido manter esse princípio em vigor? Sob a lógica do mercado, tal princípio não perde a sua função ordenadora, na medida em que as instituições públicas e privadas encontram-se de igual para igual dentro do mercado? É claro que essas perguntas mexem com uma tradição cultural de longa data, pois vêm questionar sobretudo o papel da Igreja na sociedade contemporânea. 
Em terceiro lugar, seria preciso perguntar qual, afinal, poderia ser o novo modelo - tendo em vista as novas condições - de distribuição da responsabilidade pelo cumprimento da tarefa "educação". Considera-se improvável que a mão invisível do mercado possa resolver esse problema, que se sabe que é essencial para a institucionalização dos processos educativos.

Por fim, em quarto lugar, é necessária uma derradeira reflexão sobre a interconexão perigosa de três fatores que, ao que tudo indica, reforçam-se mutuamente. Como já visto, o princípio de subsidiariedade apoia ou a ideologização, ou a burocratização do trabalho educativo; as instituições exigem de seus profissionais que eles se identifiquem com as diretrizes do detentor da entidade educativa; então, o que sobra do compromisso dos profissionais, enquanto educadores, para com as diretrizes de sua razão científica? A convicção profissional terá de curvar-se ao ditado ideológico? Como impedi-lo?

Essas perguntas alertam, apenas, para a complexidade dos problemas que nascem do modo como o projeto liberal vem imiscuindo-se e mexendo no processo de institucionalização do sistema de educação. Trata-se de dúvidas que levam a questões, por enquanto, periféricas e subestimadas nos atuais debates mantidos na área pedagógica. Parece-me, por isso, tanto mais urgente torná-las objeto de uma investigação mais ampla.

\section{Notas}

1 Este processo foi encaminhado, na Europa, pelas assim chamadas Reformas de Bolonha, de 1999. Ver, sobre isso, Wolfgang Neuser (2006, p. 389-399).

2 No campo da Pedagogia Social, a avaliação dos projetos recorre, em primeira linha, a indicadores econômicos, que decidem sobre seu financiamento.

3 Acerca desse tema, ver a contribuição de Dirk Stederoth (2017), em artigo publicado nesta mesma edição da Revista Espaço Pedagógico.

4 Ver, a respeito, Richard Scott (1968, p. 201-216).

5 Na Constituição alemã de 1949 (nos artigos 137, 138, 139, que remetem à Constituição de Weimar), e concretamente no $\S 118$ do Betriebsverfassungsgesetz (Lei da constituição da empresa) (DEUTSCHER BUNDESTAG, 2001), consta o direito dos mantenedores de entidades religiosas e educativas de definir normas próprias para a área trabalhista.

6 Sobre o princípio de subsidiariedade, ver, entre outros, Baracho (1997).

7 Embora pouco importante na tradição alemã, percebe-se um avanço tímido de universidades privadas. Uma tendência favorecida também pela abertura do campo de educação para estruturas de mercado.

\section{Referências}

BARACHO, José A. de Oliveira. O princípio de subsidiariedade: conceito e evolução. Rio do Janeiro: Forense, 1997.

BRASIL. Constituição da República Federativa do Brasil de 1988. Brasília, DF: Senado Federal; Centro Gráfico, 1988. 
. Lei no 9.394, de 1996. Estabelece as diretrizes e bases da educação nacional. Diário Oficial da União, Brasília, 23 dez. 1996.

DEUTSCHER BUNDESTAG. Betriebsverfassungsgesetz. Berlin: Deutscher Bundestag, 2001. (Lei da Constituição da Empresa).

. Grundgesetz. Bonn: Deutscher Bundestag, 1949. (Lei Fundamental da República Federal da Alemanha).

HEGEL, G. W. F. Filosofia do direito. São Leopoldo, RS: Editora Unisinos, 2010.

HUMBOLDT, W. v. Gesammelte Schriften: Band II. Francfort am Main: De Gruyer, 1988.

NEUSER, Wolfgang. O Processo de Bolonha e sua implementação na Alemanha. In: AUDY, Jorge; MOROSINI, Marília (Org.). Inovação e empreendedorismo na Universidade. Porto Alegre: EdiPUCRS, 2006. p. 389-399.

SCOTT, Richard. Konflikte zwischen Spezialisten und Bürokraten. In: MAYNTZ, Renate (Org.). Bürokratische Organisation. Köln: Kiepenheuer \& Witsch, 1968. p. 201-216.

STEDEROTH, Dirk. Formação ajustada: sobre a capitalização do humano na formação e sua administração total. Revista Espaço Pedagógico, Passo Fundo, v. 24 n. 3, set./dez. 2017. (No prelo). 